\title{
Gene-Silencing Screen for Mammalian Axon Regeneration Identifies Inpp5f (Sac2) as an Endogenous Suppressor of Repair after Spinal Cord Injury
}

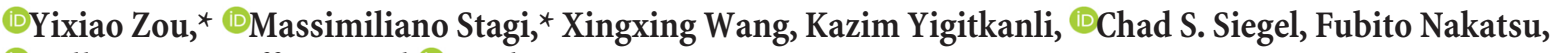 \\ ㄴ.William B. J. Cafferty, and ${ }^{-S t e p h e n ~ M . ~ S t r i t t m a t t e r ~}$ \\ Cellular Neuroscience, Neurodegeneration and Repair Program, Interdepartmental Neuroscience Program, Departments of Neurology and Neurobiology, \\ Yale University School of Medicine, New Haven, Connecticut 06536
}

Axonal growth and neuronal rewiring facilitate functional recovery after spinal cord injury. Known interventions that promote neural repair remain limited in their functional efficacy. To understand genetic determinants of mammalian CNS axon regeneration, we completed an unbiased RNAi gene-silencing screen across most phosphatases in the genome. We identified one known and 17 previously unknown phosphatase suppressors of injury-induced CNS axon growth. Silencing Inpp5f (Sac2) leads to robust enhancement of axon regeneration and growth cone reformation. Results from cultured Inpp $5 \mathrm{f}^{-1-}$ neurons confirm lentiviral shRNA results from the screen. Consistent with the nonoverlapping substrate specificity between Inpp5f and PTEN, rapamycin does not block enhanced regeneration in Inpp5f $\mathrm{f}^{-l-}$ neurons, implicating mechanisms independent of the PI3K/AKT/mTOR pathway. Inpp5 $\mathrm{f}^{-1-}$ mice develop normally, but show enhanced anatomical and functional recovery after mid-thoracic dorsal hemisection injury. More serotonergic axons sprout and/or regenerate caudal to the lesion level, and greater numbers of corticospinal tract axons sprout rostral to the lesion. Functionally, Inpp5fnull mice exhibit enhanced recovery of motor functions in both open-field and rotarod tests. This study demonstrates the potential of an unbiased high-throughput functional screen to identify endogenous suppressors of CNS axon growth after injury, and reveals Inpp5f (Sac2) as a novel suppressor of CNS axon repair after spinal cord injury.

Key words: axon regeneration; inositol phosphate; sac2; siRNA; spinal cord injury

Significance Statement

The extent of axon regeneration is a critical determinant of neurological recovery from injury, and is extremely limited in the adult mammalian CNS. We describe an unbiased gene-silencing screen that uncovered novel molecules suppressing axonal regeneration. Inpp5f (Sac2) gene deletion promoted recovery from spinal cord injury with no side effects. The mechanism of action is distinct from another lipid phosphatase implicated in regeneration, PTEN. This opens new pathways for investigation in spinal cord injury research. Furthermore the screening methodology can be applied on a genome wide scale to discovery the entire set of mammalian genes contributing to axonal regeneration.

\section{Introduction}

Spinal cord injury (SCI) is a debilitating condition without effective medical treatment. Enhancing axon growth after injury is an

\footnotetext{
Received May 2, 2015; revised June 9, 2015; accepted June 12, 2015.

Author contributions: Y.Z., M.S., X.W., K.Y., C.S.S., F.N., W.B.J.C., and S.M.S. designed research; Y.Z., M.S., X.W., K.Y., and C.S.S. performed research; F.N. contributed unpublished reagents/analytic tools; Y.Z., M.S., X.W., K.Y., C.S.S., and S.M.S. analyzed data; Y.Z., M.S., X.W., K.Y., F.N., W.B.J.C., and S.M.S. wrote the paper.

We acknowledge National Science Foundation Graduate Research Fellowship and National Institutes of Health (NIH) Predoctoral Fellowship support to Y.Z., and research support from the NIH and the Falk Medical Research Trust to S.M.S. We thank Stefano Sodi and Yiguang Fu for technical assistance.

*Y.Z. and M.S. contributed equally to this work.

The authors declare no competing financial interests.

Correspondence should be addressed to Stephen M. Strittmatter, Cellular Neuroscience, Neurodegeneration and Repair Program, Interdepartmental Neuroscience Program, Departments of Neurology and Neurobiology, Yale University School of Medicine, New Haven, CT 06536. E-mail: stephen.strittmatter@yale.edu.
}

attractive strategy for therapeutic intervention. Targeting inhibitory ligands such as CSPG (Bradbury et al., 2002), Nogo (Chen et al., 2000; GrandPré et al., 2000), MAG (Mukhopadhyay et al., 1994), and OMgp (Wang et al., 2002), or their neuronal receptors and signal transduction factors such as NgR1 (Fournier et al., 2001; Kim et al., 2004), PirB (Atwal et al., 2008), PTPRS (Lang et al., 2015), RhoA (Dergham et al., 2002), and ROCK (Fournier et

\footnotetext{
M. Stagi's present address: Institute of Translational Medicine, University of Liverpool, Liverpool L69 3BX, United Kingdom.

F. Nakatsu's present address: Department of Neurochemistry and Molecular Cell Biology, Graduate School of Medical and Dental Sciences, Niigata University, Niigata 951-8510, Japan.

K. Yigitkanli's present address: Polatli Hospital, Ministry of Health, Ankara 06900, Turkey.

DOl:10.1523/JNEUROSCI.1718-15.2015

Copyright $\odot 2015$ the authors $\quad 0270-6474 / 15 / 3510429-11 \$ 15.00 / 0$
} 
al., 2003), or targeting inhibitory factors intrinsic to injured neurons, such as PTEN (Park et al., 2008), PDE4 (Nikulina et al., 2004), KLF4 (Moore et al., 2009), and SOCS3 (Smith et al., 2009), have led to enhanced axon growth and recovery in various preclinical models. Despite remarkable progress, we still lack a complete understanding of the repertoire of genetic factors that restrict recovery after CNS trauma. From a therapeutic perspective, identification of novel suppressors of axon growth is important for developing single-agent as well as combinatorial therapeutics (Cafferty et al., 2010; Sun et al., 2011; Lewandowski and Steward, 2014).

Functional genetic screens have the potential to uncover new pathways that regulate axon regeneration. PTEN, as a suppressor of regeneration, was identified from a survey of six genes in optic nerve regeneration (Park et al., 2008). KLF4's role is derived from overexpressing 111 developmentally regulated genes in hippocampal neurite outgrowth (Moore et al., 2009). Overexpression screens of cortical neurite outgrowth have revealed novel axon growth regulators (Blackmore et al., 2010; Buchser et al., 2010). The role of DLK-1 (MAP3K12) as a kinase required for initiation of regeneration was revealed by an unbiased RNAi lossof-function screen in GABAergic axons of Caenorhabditis elegans (Hammarlund et al., 2009). Furthermore, identification of EFA-6 from a screen using C. elegans mutant alleles (Chen et al., 2011) substantially added to our understanding of how microtubule stability contributes to axon regeneration (Ertürk et al., 2007; Hellal et al., 2011). To date, a loss-of-function screen tailored to identify endogenous suppressors of axon regeneration in mammalian primary CNS neurons has not been reported.

We focused on phosphatases because of their limited number in the mammalian genome $(<300)$, the relative feasibility of developing small molecule inhibitors to block phosphatases, and known examples of phosphatases acting as suppressors of CNS regeneration. For instance, protein tyrosine phosphatase, receptor S (PTPRS) serves as a receptor to extrinsic inhibitor CSPG (Shen et al., 2009). The related phosphatase, LAR, may cooperate with PTPRS as a CSPG receptor (Fry et al., 2010; Fisher et al., 2011). PTEN is a lipid phosphatase that metabolizes $\mathrm{PI}(3,4,5) \mathrm{P} 3$ and suppresses axon regeneration by negatively regulating the PI3K/mTOR pathway (Park et al., 2008).

Here, we report an RNAi-mediated functional screen to identify phosphatases that inhibit axon regeneration in mouse cortical neurons. We identified 18 phosphatase suppressors from the screen, including one known inhibitor of axon growth (PTEN) and 17 novel genes. We report enhanced axon growth and functional recovery after SCI in mice with targeted deletion of one phosphatase hit, Inpp5f (Sac2). These findings validate this functional genomics approach and establish Inpp5f inactivation as a potential therapeutic approach to improve recovery after SCI.

\section{Materials and Methods}

Cortical axon regeneration screen. Cortices from E17.5 C57BL/6 mice embryos were dissected in ice-cold Hibernate E Minus Calcium medium (catalog \#HE-Ca; BrainBits) and incubated in $5 \mathrm{ml}$ of digestion medium for $30 \mathrm{~min}$ at $37^{\circ} \mathrm{C}$. The digestion medium contains papain $(25 \mathrm{U} / \mathrm{ml}$; catalog \#LS003127; Worthington Biochemical), DNAse I (2000 U/ml; catalog \#10104159001; Roche), 2.5 mм EDTA, and $1.5 \mathrm{~mm} \mathrm{CaCl}_{2}$ diluted in plating medium. Plating medium is composed of $500 \mathrm{ml} \mathrm{Neurobasal} \mathrm{A}$ (catalog \#10888-022; Life Technologies) supplemented with $5 \mathrm{ml}$ of 100 mM sodium pyruvate (catalog \#11360-070; Life Technologies), $5 \mathrm{ml}$ of $100 \times$ GlutaMAX (catalog \#35050-061; Life Technologies), $5 \mathrm{ml}$ of $100 \times$ penicillin-streptomycin (catalog \#15140-122; Life Technologies), and 10 $\mathrm{ml}$ of 50× B-27 supplement (catalog \#17504-001; Life Technologies). Digested tissues were washed once in $10 \mathrm{ml}$ Neurobasal A medium, trit- urated $10-15$ times in $1.5 \mathrm{ml}$ of plating medium, and then passed through a $40 \mu \mathrm{m}$ cell strainer (catalog \#352340; Corning) to remove large chunks of debris. Cells were plated on 96-well poly-lysine-coated plates (catalog \#354413; Corning) at a density of 50,000 cells per well in $200 \mu \mathrm{l}$ of plating medium. Lentiviral particles targeting 219 phosphatases using 1086 unique shRNA clones (SM0431; Sigma) were added on DIV 5 to achieve a minimum multiplicity of infection of 10. On DIV 8, 96-well cultures were scraped using a custom-fabricated 96-pin array as described previously (Huebner et al., 2011) and allowed to regenerate for another $72 \mathrm{~h}$ before fixing with $4 \%$ paraformaldehyde. Regenerating axons in the scrape zone were visualized using an antibody against $\beta 3$ tubulin (1:2000, mouse monoclonal; catalog \#G712A; Promega). Growth cones were visualized by staining for F-actin using Alexa 568conjugated phalloidin (10 nM; catalog \#A12380; Life Technologies). Cell density was visualized using nuclear marker DAPI $(0.2 \mu \mathrm{g} / \mathrm{ml}$; catalog \#D9542; Sigma). Images were taken on a $10 \times$ objective in an automated high-throughput imager (ImageXpress Micro XLS; Molecular Devices) under identical conditions. Regeneration zone identification, image thresholding, and quantitation were performed blind to treatment conditions either in ImageJ or using an automated MATLAB script.

Characterization of INPP5F/Inpp5f $m R N A$ expression. INPP5F expression in different adult human tissues was measured using RNA-seq by the Illumina Human Body Map 2.0 project. Data were accessed via NCBI AceView (http://www.ncbi.nlm.nih.gov/IEB/Research/Acembly/ av.cgi? $\mathrm{db}=$ human $\& \mathrm{c}=$ Gene\&l $=\mathrm{INPP} 5 \mathrm{~F})$. For comparison, human brain expression of PTEN was accessed from the same database (http://www.ncbi. $\mathrm{nl}$ m.nih.gov/IEB/Research/Acembly/av.cgi?db=human \&c= G e n e \& l=P T E N). To quantify the extent of Inpp5f gene knockdown after treating with lentiviral shRNA particles, total RNA was harvested from cortical culture in 96-well plates $3 \mathrm{~d}$ after adding viruses by applying $30 \mu \mathrm{l}$ of TRIzol reagent (catalog \#15596-026; Life Technologies) to each well. To quantify levels of Inpp5f mRNA expression in different brain regions before or $7 \mathrm{~d}$ after SCI, mice were deeply anesthetized by $\mathrm{CO}_{2}$ and decapitated. Different brain regions were rapidly dissected on ice and snap frozen in liquid nitrogen. One milliliter of TRIzol reagent was later added per 50-100 mg of tissue. Total RNA was prepared according to the TRIzol reagent protocol. cDNA was then produced by assembling the following reverse transcription PCR: $1 \mu \mathrm{g}$ of total RNA, $0.5 \mu \mathrm{l} \mathrm{M-MuLV}$ Reverse Transcriptase and $2.5 \mu \mathrm{l} 10 \times$ buffer (enzyme at 200,000 U/ml stock concentration; catalog \#M0253S; New England BioLabs), $1.5 \mu \mathrm{l}$ Random Primer 9 (50 $\mu$ M stock; catalog \#S1254S; New England BioLabs), $1 \mu$ l dNTP (10 mM stock' catalog \#U151A; Promega), and brought to $25 \mu \mathrm{l}$ total reaction volume with DEPC water. PCR program is $30^{\circ} \mathrm{C}$ for $10 \mathrm{~min}, 42^{\circ} \mathrm{C}$ for $40 \mathrm{~min}$, and $99^{\circ} \mathrm{C}$ for $5 \mathrm{~min}$. cDNA of each sample was then used for real-time qPCR in the following reaction: $1 \mu \mathrm{l}$ cDNA,

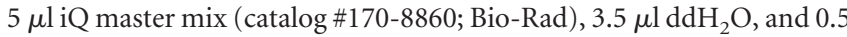
$\mu \mathrm{l}$ gene expression assay targeting mouse Inpp5f (20X stock, Mm00724391 mlp Life Technologies). qPCR was performed on a BioRad CFX Connect Real-Time PCR Detection System using standard cycles. GAPDH was used as loading control. Three biological samples were used per condition. Each sample was loaded in triplicates.

Localization of Inpp5f protein in neurons. Primary mouse cortical neurons were dissociated from E17.5 mice embryos as described above and seeded on $18 \mathrm{~mm}$ poly-D-lysine-coated glass coverslips at a density of $40,000 \mathrm{cells} / \mathrm{cm}^{2}$. Five coverslips were housed in each $60 \mathrm{~mm}$ Petri dish containing $3 \mathrm{ml}$ of medium. During initial plating, plating medium as described above was supplemented with 1\% FBS (catalog \#16000-044; Life Technologies). Four hours after plating, medium was replaced to FBS-free plating medium. One milliliter of medium was removed and 2 $\mathrm{ml}$ of fresh medium was added every $7 \mathrm{~d}$. On DIV 16, neurons were double transfected with C-terminal GFP-tagged, full-length mouse Inpp5f and cytosolic tdTomato constructs using the calcium phosphate method. On DIV 21, neurons were imaged live on a spinning disk confocal microscope (UltraVIEW; PerkinElmer).

Sensitivity to rapamycin inhibition. Single-embryo primary cortical cultures were prepared from E17.5 pregnant Inpp $5 \mathrm{f}^{+/-}$females mated with Inpp $5 \mathrm{f}^{+/-}$males. Tail clips were saved from each embryo for later genotyping. Dissection, trituration, and plating were all performed separately for each embryo. Care was taken to avoid cross-contamination. 


\section{a}
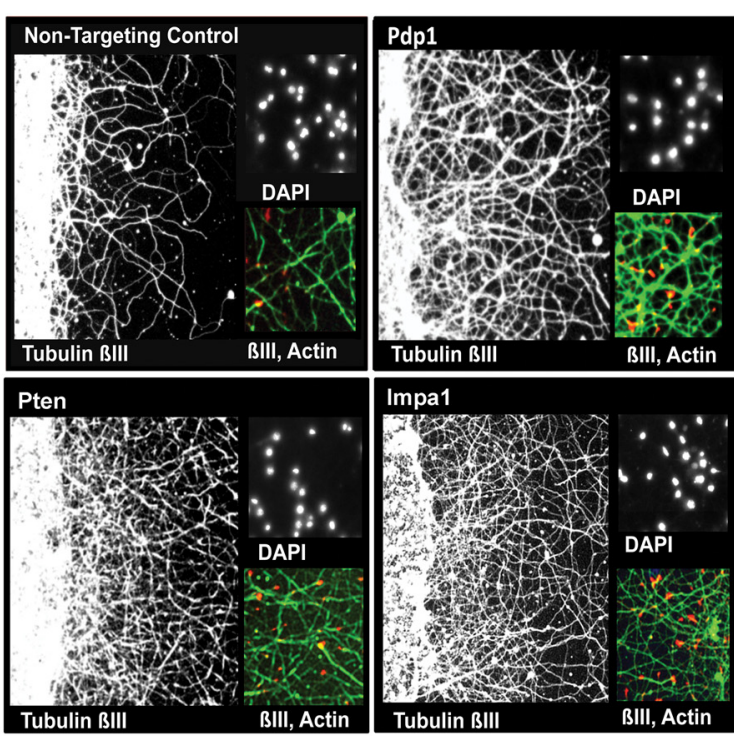

b

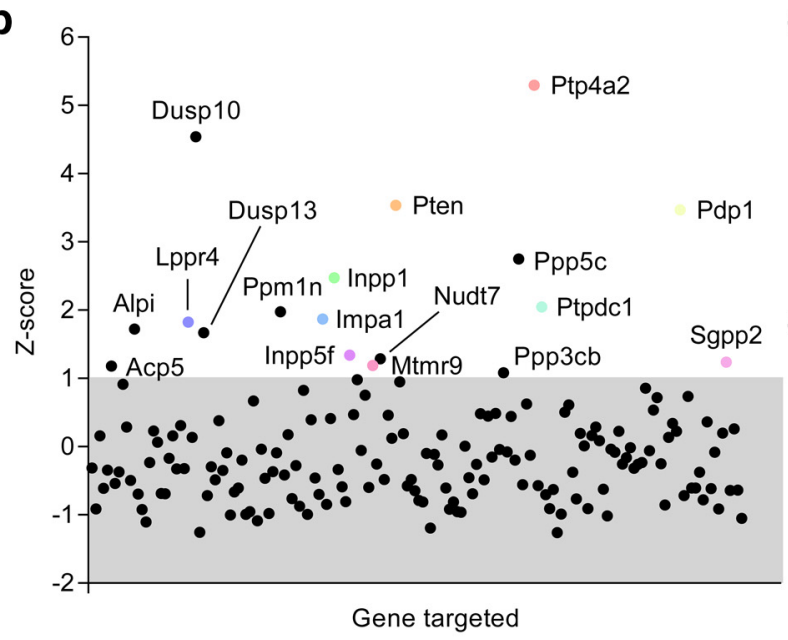

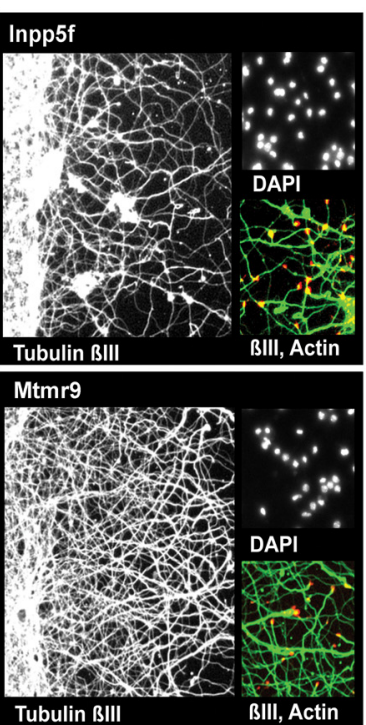

c
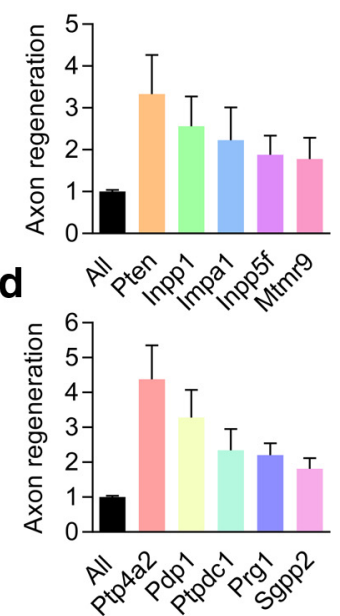

Figure 1. RNAi-mediated functional screen identifies phosphatase suppressors of CNS axon growth after injury. $\boldsymbol{a}$, Images from the RNAi-mediated functional screen. Each of the six large parts is from a different shRNA species, as indicated. The largest of the three subparts from each case shows $\beta$ III-tubulin staining of axonal growth. The uninjured zone is at the extreme left border and the right $80 \%$ of the micrograph shows the extent of regenerative growth. Note that knockdown of each of these five genes increased axonal regeneration. Upper right, DAPI staining of cell nuclei in the uninjured zone. There is no consistent difference in cell density or cell survival with these shRNAs. The density of cell nuclei in the scraped zone is very low, $<2 \%$ of that in the uninjured zone (data not shown). Bottom right, $\beta$ III-tubulin of axons (green) together with phalloidin staining of F-actin (red) to illustrate regenerating axonal growth cones. $\boldsymbol{b}, Z$-scores of all phosphatases screened. Gene names of all phosphatases with a Z-score $>1$ (i.e., above the gray-shaded zone) are labeled. c, Fold change in regeneration after knocking down phosphatases that metabolize water-insoluble and water-soluble inositol phosphates. The data for each gene are pooled from $n=8-10$ values, derived from four to five shRNAs each assayed in duplicates, mean \pm SEM. $\boldsymbol{d}$, Fold change in regeneration of several other top hits from the phosphatase screen.

As described above, neurons were plated at 50,000 cells per well in $200 \mu \mathrm{l}$ of plating medium on 96-well plates. Fifty percent medium change was performed every $7 \mathrm{~d}$. Scrape injury occurred on DIV 12 and immediately afterward, cultures either received rapamycin (300 nM; LC Laboratories; R-5000) or DMSO vehicle control diluted in plating medium. Final DMSO concentration is $0.0005 \%$ for both treatment groups. Seventytwo hours after scrape, culture was fixed and stained for DAPI and $\beta 3$ tubulin. To test whether enhanced axon regeneration after PTEN inactivation is sensitive to rapamycin inhibition in the scrape assay, primary cortical neurons were prepared from E17.5 WT embryos as described above and cotransfected with either myristoylated GFP plus nontargeting shRNA (SHC002; Sigma) constructs or myristoylated GFP plus mouse PTEN shRNA (SHCLND-NM 008960 TRCN0000028992;
Sigma) constructs using the Amaxa Mouse Neuron Nucleofector Kit (VPG-1001; Lonza). Neurons $\left(8 \times 10^{6}\right)$ were mixed with $5 \mu \mathrm{g}$ of total DNA (1:1 ratio between GFP and shRNA) for each nucleofection reaction under conditions listed in manufacturer's protocol. Nucleofected neurons were plated at 60,000 cells per well in $200 \mu \mathrm{l}$ of plating medium on 96-well plates. On every seventh day, 50\% of the culture medium was replaced with fresh medium. Scrape injury occurred on DIV 8 and immediately afterward cultures either received rapamycin (300 $\mathrm{nm}$ ) or DMSO vehicle control diluted in plating medium. Final DMSO concentration is $0.0005 \%$ for both treatment groups. Seventy-two hours after scrape, cultures were imaged live and GFP + processes that regenerated into the scraped region were quantified in ImageJ. Immunostaining for phospho-S6 ribosomal protein (catalog \#2211; Cell Signaling Technology; 1:100) and Western blot for phospho-mTOR (catalog \#5536; Cell Signaling Technology; 1:1000), mTOR (catalog \#2983; Cell Signaling Technology; 1:1000), and actin (catalog \#3700; Cell Signaling Technology) were performed by following standard protocols using primary antibodies as indicated.

Mice and surgeries. Inpp5 $\mathrm{f}^{-1-}$ mice is a gift from Dr. Jonathan Epstein, University of Pennsylvania (Zhu et al., 2009). All experimental procedures were performed in compliance with animal protocols approved by the Institutional Animal Care and Use Committee at Yale University. For genotyping, genomic DNA was extracted from ear clip samples using REDExtract-N-Amp Tissue PCR Kit (catalog \#XNAT; Sigma) and genotyped with the following primers: Wt fwd '5-TTA CCT GCT GTT CAT GTC TGT GGC-3'; Wt rev '5CAC CAA TAG CTG ACC ATC CAG AGC-3'; Mut fwd '5-ATA TTG AAA CCC ACG GCA TGG TGC-3'; Mut rev '5-TTT GAT GGA CCA TTT CGG CAC AGC-3'. The wild-type amplicon is $214 \mathrm{bp}$ and the mutant amplicon is 323 bp. Wild-type and mutant reactions were run separately using a touchdown PCR protocol. Adult (3-5 months old) female Inpp5f $\mathrm{f}^{-/-}$ mice and their littermate controls (including both Inpp5f $\mathrm{f}^{+/-}$and WT animals) were used for SCI experiments. All animals received a subcutaneous injection of Buprenex $30 \mathrm{~min}$ before surgery at $0.1 \mathrm{mg} / \mathrm{kg}$. Mice were first anesthetized with $4 \%$ isoflurane and maintained with 3\% isoflurane throughout the procedure. Dorsal hemisection was performed as described previously (Duffy et al., 2012). First, dorsal spinal cord was exposed at T6 and T7 levels by laminectomy. Dura mater was then pierced and a pair of microscissors was used to lesion the spinal cord to a depth of $1.0 \mathrm{~mm}$ to completely sever the dorsal and dorsolateral corticospinal tract (CST). Lateral aspect of the spinal cord was scraped with a 30 gauge needle to ensure completeness of the lesion. Muscle and skin overlying the lesion were sutured with 4.0 vicryl. All animals received subcutaneous injection of $100 \mathrm{mg} / \mathrm{kg}$ ampicillin and 0.1 $\mathrm{mg} / \mathrm{kg}$ Buprenex twice a day for the first $2 \mathrm{~d}$ after surgery and additional injections later as necessary.

Tracing. To trace the CST, biotin dextran amine (BDA; $0.1 \mathrm{~g} / \mathrm{ml}$ in sterile $\mathrm{ddH}_{2} \mathrm{O}, \mathrm{MW}=10,000$, catalog \#D-1956; Life Technologies) was injected into the sensorimotor cortex to anterogradely label the CST. In 
each animal, $300 \mathrm{nl}$ of BDA was injected at each of the five sites (coordinates from bregma in mediolateral/anterior-posterior format in $\mathrm{mm}: 1.0 / 0.0,1.5 / 1.5,1.5 / 0.5,1.5 /-0.5,1.5 /$ $-1.5)$ for a total of $1.5 \mu \mathrm{l}$ volume. Mice were kept for an additional $14 \mathrm{~d}$ before being killed.

Histology and immunohistochemistry. Mice were given a lethal dose of anesthesia and transcardially perfused with $4 \%$ paraformaldehyde. Brains and spinal cords were isolated, embedded in $10 \%$ gelatin, and postfixed in $4 \%$ paraformaldehyde overnight at $4^{\circ} \mathrm{C}$. Serial sections $(40 \mu \mathrm{m})$ were collected on a vibratome (VT1000S; Leica). Transverse sections were collected at C7 cervical enlargements and L2 lumbar enlargements. Furthermore, a $10 \mathrm{~mm}$ block of spinal cord including the thoracic lesion site (from $-5 \mathrm{~mm}$ rostral to $+5 \mathrm{~mm}$ caudal) was excised from each animal and sectioned sagittally, collecting every single section. In addition, a block of tissue was excised immediately anterior to the sagittally sectioned block and sectioned transversely. Severity of lesion was quantified via phase-contrast microscopy by measuring the length of intact cord at the lesion center and the length of total cord sufficiently removed from the lesion center on every sagittal section using phase-contrast microscopy. To detect 5-HT (or serotonin), sections were blocked and permeabilized in a solution consisting of $10 \%$ normal donkey serum (NDS) and $0.2 \%$ Triton X-100 in PBS

$(0.2 \%$ PBST $)$ for $1 \mathrm{~h}$ at room temperature. Primary antibodies $(1: 10,000$; rabbit polyclonal; catalog \#20080; ImmunoStar) were diluted in 5\% NDS and $0.2 \%$ PBST and incubated with sections at $4^{\circ} \mathrm{C}$ overnight. Sections were washed $3 \times$ for 10 min each in PBS. Alexa 555-conjugated donkey anti-rabbit secondary antibody (1:500; donkey-anti-rabbit; catalog \#A31572; Life Technologies) was applied for $2 \mathrm{~h}$ in room temperature. To detect BDA-labeled fibers, BDA staining was performed using a tagged avidin reaction (Vectastain ABC; catalog \#PK-4000; Vector Laboratories) and following protocols of the TSA cyanine 3 amplification system (catalog \#NEL744001KT; PerkinElmer).

Axonal counting and quantifications. All quantification was performed blind to genotypes. To quantify total CST axons labeled, BDA+ CST fibers were counted in the dorsal column CST bundle at the level of cervical enlargement. Images were collected on a confocal microscope (LSM710; Zeiss) with $63 \times$ objective. Axons were counted in three representative rectangular areas $\left(6000 \mu \mathrm{m}^{2}\right)$ per section on two sections. The number of labeled axons was calculated by adjusting counted area to total area of the main CST bundle. To quantify the number of CST sprouting axons in transverse sections, a vertical line was drawn at 200 $\mu \mathrm{m}$ ipsilateral to the sagittal midline and all BDA+ fibers that cross the line were counted. For each mouse, at least six sections were imaged using $20 \times$ objective on LSM710 and analyzed. Density of sprouting CST fibers near the lesion were quantified by drawing vertical lines at $-5,-3,-2$, $-1,0,1,2$, and $3 \mathrm{~mm}$ from the lesion on the computer screen and the number of BDA + fibers outside the main CST bundle crossing each line was counted under a $20 \times$ objective lens on a Zeiss Z1 Imager. Every section of the whole spinal cord was analyzed. To quantify the density of $5-\mathrm{HT}+$ axons innervating the ventral horns in transverse sections, a line $500 \mu \mathrm{m}$ long that bisects the ventral horn was drawn at each ventral horn. The number of 5-HT+ axons crossing the line was counted in both ventral horns on each section. At least three sections from each mouse were imaged using $20 \times$ objective on LSM710 and analyzed.

Behavioral testing. All behavioral tests were performed by two researchers unaware of the genotype of the mice. We used the Basso Mouse Scale (BMS) as a measure of open-field locomotion (Basso et al., 2006). BMS has a quantitative scale from 0 to 9 . Observations were made once pre-injury and weekly following hemisection. Rotarod (Columbus In-

b High titer virus d

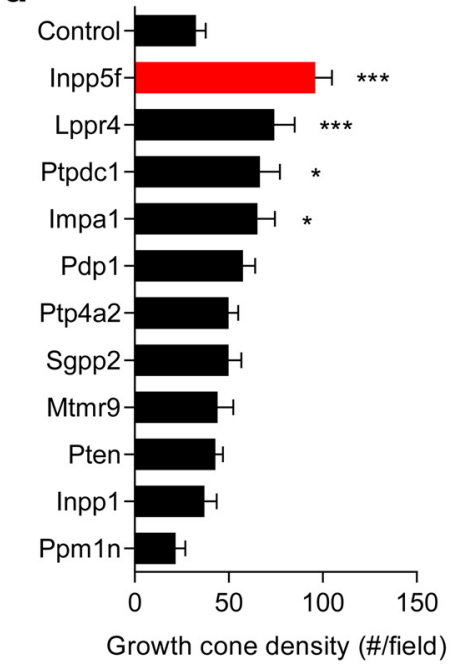

Figure 2. $\operatorname{lnpp5f}(\mathrm{SaC2})$ silencing increases CNS axon growth and growth cone formation after injury. $\boldsymbol{a}$, Protein domain organization of human INPP5F. $\boldsymbol{b}$, Silencing Inpp5f using an independent preparation of high-titer shRNA lentiviral particles C
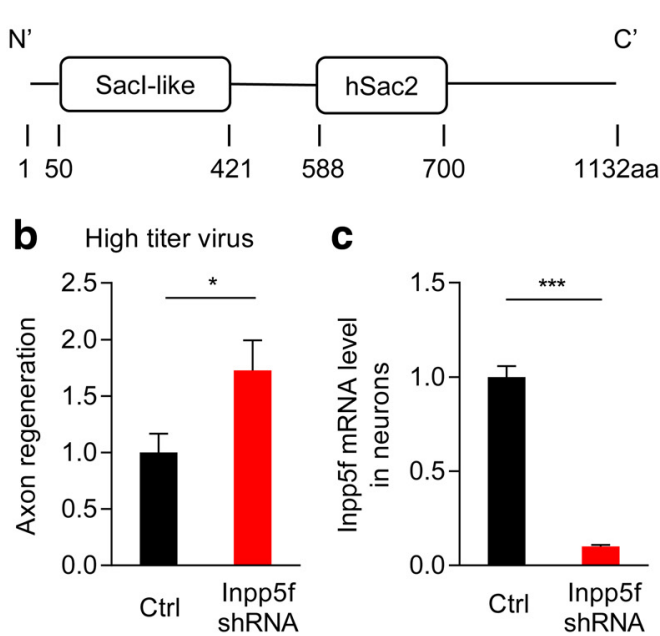
c

(1)

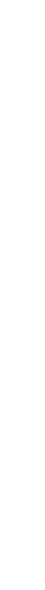


a

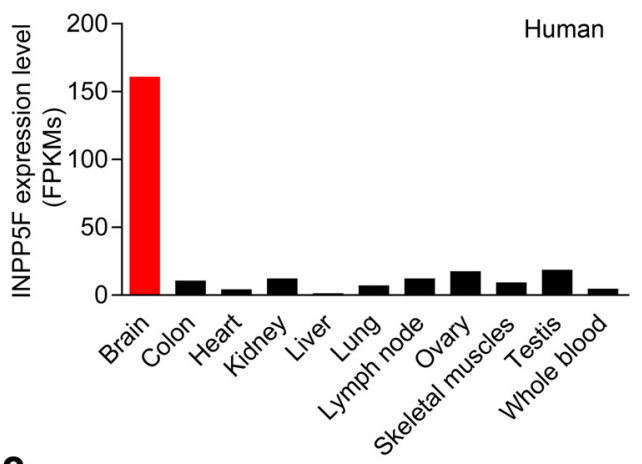

C

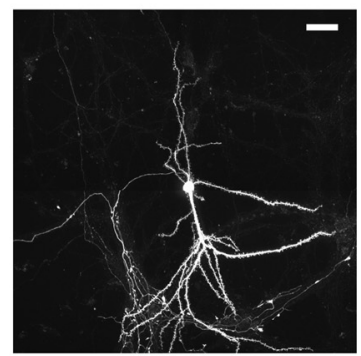

Inpp5f::GFP

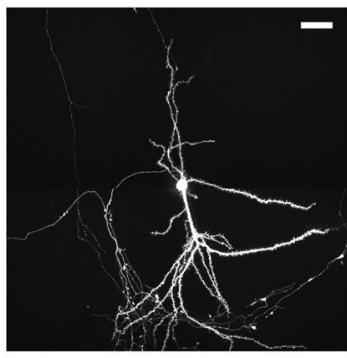

tdTomato b

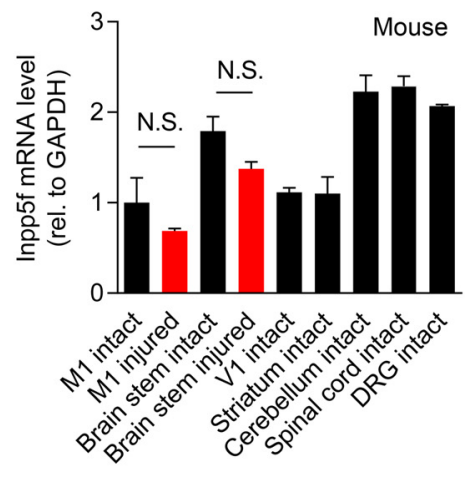

myotubularin-related phosphatases. Mtmr9 forms heterodimers with Mtmr6, 7, and 8 to facilitate removal of 3-phosphate from $\mathrm{PI}(3) \mathrm{P}, \mathrm{PI}(3,5) \mathrm{P} 2$, and water-soluble inositol 1,3 bisphosphate, Ins $(1,3) \mathrm{P} 2$ (Zou et al., 2012). The product of two other hit genes regulate water-soluble inositol phosphates (Majerus, 1992). Inpp1 removes 1-phosphate from $\operatorname{Ins}(1,3,4) \mathrm{P} 3$ and $\operatorname{Ins}(1,4) \mathrm{P} 2$. Impa1 removes the single phosphate from $\operatorname{Ins}(1) \mathrm{P}$, Ins(3)P, and $\operatorname{Ins}(4) \mathrm{P}$.

\section{Silencing Inpp5f (Sac2) leads to robust axon regeneration with increased growth cones}

To validate putative suppressors identified from the primary screen, we obtained high-titer lentiviral shRNA particles targeting each one as well as nontargeting controls and repeated the axon regeneration assay. In addition to assessing $\beta$ IIItubulin + regrowth $72 \mathrm{~h}$ after scrape, we quantified density of growth cones (Phalloidin + puncta at the tip of $\beta$ IIItubulin + axons) in the injury zone (Figs. $1 a, 2 d)$. Suppressing Inpp5f expression leads to robust increases both in $\beta \mathrm{III}-$ tubulin + axon regrowth and density of growth cones (Fig. 2b). Of the 18 genes scored as hits on our axonal regeneration screen, Inpp5f scored consistently as the RNAi that most strongly increased the

Figure 3. Tissue level and subcellular expression patterns of INPP5F/Inpp5f. $\boldsymbol{a}$, Human INPP5F expression is highly enriched in the adult brain. Data are from the Illumina Human Body Map 2.0. $\boldsymbol{b}$, Inpp5f is widely expressed in the adult mouse brain at the mRNA level. Expression persists in primary motor cortex and brainstem after dorsal hemisection injury of the spinal cord. Tissues were harvested $7 \mathrm{~d}$ after injury. Data are mean \pm SEM for $n=3$ mice. N.S., $p>0.05$, Student's $t$ test. Each sample was tested in triplicate per condition. c, Inpp5f::GFP fusion protein expressed in DIV 21 primary mouse cortical neurons is localized in the cytoplasm of soma, dendrites, and axons, matching the pattern of coexpressed cytosolic marker, tdTomato. Scale bar, $50 \mu \mathrm{m}$.

mally to the regeneration signal, which is primarily axonal. Plates were imaged using a high-content imaging system and parameters relevant to regeneration were quantified using automated analysis algorithms (MATLAB and ImageJ). In particular, we quantified the level of $\beta$ III-tubulin-immunoreactive axon regrowth into the scraped area and density of nuclei in unscraped region adjacent to the scrape zone (Fig. 1a). To eliminate biases due to variations in regeneration from plate to plate, we normalized $\beta$ III-tubulin + regeneration in each well by the averaged level of regeneration across 96 wells on the same plate. The entire screen was performed twice on duplicated sets of plates. We pooled all wells across two replicates that received shRNA clones targeting the same phosphatase and computed the mean and variance of regeneration for each phosphatase targeted. To rank the phosphatases and identify the strongest suppressors of injuryinduced axon regeneration, we defined a $Z$-score for each targeted phosphatase as the number of SDs that the gene-specific mean differs from the grand mean. Because regeneration levels are normalized on each plate, the grand mean is one. With this measure, we identified 18 phosphatases with a $Z$-score $>1$ for further consideration (Fig. 1b).

A group of phosphatases that regulates inositol phosphate metabolism was prominent among the hit genes (Fig. 1c). Aside from PTEN, which removes the 3-phosphate from $\mathrm{PI}(3,4,5) \mathrm{P} 3$, the proteins encoded by two other hit genes regulate phosphoinositide metabolism. Inpp5f is a 4-phosphatase whose substrate is PI4P (Hsu et al., 2015; Nakatsu et al., 2015), although previous studies have suggested it acts a 5-phosphatase, which removes the 5-phosphate group from PI(4,5)P2 and PI(3,4,5)P3 (Minagawa et al., 2001; Zhu et al., 2009). Mtmr9 is a catalytically inactive member of the density of growth cones formed in the scrape region. Consistent with the strong effect of shRNA lentiviral particles targeting Inpp5f, the Inpp5f mRNA transcript was suppressed by $>90 \%$ in primary cortical cultures (Fig. 2c). Moreover, neurons cultured from mice lacking functional Inpp5f regenerated axons more effectively than wild-type neurons (Fig. 4; data not shown).

\section{Inpp5f (Sac2) expression is consistent with suppression of recovery after SCI}

If Inpp5f functions to substantially limit neural repair after adult CNS injury, then it must be expressed in adult CNS neurons with limited regenerative phenotype. RNA-seq data expressed in fragments per kilobase of exon per million fragments mapped (FPKM) from lllumina Human Body Map 2.0 indicate that INPP5F is expressed at a higher level in adult brain than PTEN at the mRNA level. PTEN itself ranks within the top $12.5 \%$ of highest expressed genes in the adult human brain (INPP5F vs PTEN, 161 vs 65.5 FPKM, NCBI AceView). Among 16 different tissue types examined, INPP5F expression in humans is highly selective to brain (Fig. 3a). Expression level in the brain is more than eight times higher than that in the second and third highest tissue types (testes and ovary). The brain-specific pattern of Inpp5f expression reduces potential side effects that might manifest from inactivating Inpp $5 f$ in the periphery, therefore, adding to its favorable profile as a therapeutic target for clinical translation.

To investigate functions of Inpp5f in the CNS, we examined expression of mouse Inpp $5 \mathrm{f}$ with and without SCI. Mouse Inpp5f is widely expressed in the adult brain at the mRNA level, including the primary cortices, brainstem, striatum, cerebellum, spinal cord, and dorsal root ganglia (Fig. 3b). Furthermore, cortical 
expression includes all layers and brainstem expression includes the raphe nuclei in the Allen Brain Atlas (Lein et al., 2007). Furthermore, Inpp5f expression persists at high levels in mouse primary motor cortex and brainstem $7 \mathrm{~d}$ after midthoracic hemisection injury (Fig. 3b). Expression levels are comparable before and after injury. Within DIV 21 cortical neurons, the protein is observed throughout processes, in tapered dendrites and in axons (Fig. 3c). Expression data in human and mice brain support Inpp5f's role as a putative suppressor of regeneration of descending tracts and recovery of motor functions after SCI.

\section{Inpp5f and PTEN suppress CNS axon regeneration via distinct mechanisms} Because Inpp5f had been reported to metabolize $\mathrm{PI}(3,4,5) \mathrm{P} 3$ by removing the 5-phosphate group (Minagawa et al., 2001; Zhu et al., 2009), we considered whether its mechanism of action might overlap with that of PTEN. PTEN suppresses CNS axon regeneration by removing the 3-phosphate group from $\mathrm{PI}(3,4,5) \mathrm{P} 3$, therefore, reducing activation of the $\mathrm{PI} 3 \mathrm{~K} / \mathrm{mTOR}$ pathway. It is known that the mTORC1 inhibitor rapamycin abolishes the growth-enhancing effects of PTEN inactivation in optic nerve regeneration (Park et al., 2008) and compensatory sprouting from the adult corticospinal tract (Lee et al., 2014). Therefore, we tested whether increased regeneration caused by loss of Inpp5f or PTEN is sensitive to rapamycin inhibition using the scrape assay.

Inpp5f removal was achieved by using Inpp $5 \mathrm{f}^{-/-}$neurons and compared against Inpp5 $\mathrm{f}^{+/-}$or WT littermate controls. Cultures were scraped on DIV 12. PTEN removal was achieved by nucleofection of dissociated WT E17.5 cortical neurons with a validated shRNA targeting mouse PTEN and compared against the same WT neurons nucleofected with a nontargeting control shRNA. To mark transfected cells, a myristoylated GFP driven by CAG promoter construct was conucleofected with the shRNA plasmids. Eighty percent of GFP+ $\mathrm{PTEN}+$ cell bodies become GFP + PTEN - on DIV 5. Cultures were scraped on DIV 8 and only GFP+ processes were analyzed for regeneration. Rapamycin (300 nM) or DMSO vehicle of the same concentration was added to the medium immediately after scrape and maintained during regeneration (Fig. 4). Cultures were fixed at $72 \mathrm{~h}$ post injury and quantified for regeneration. Cell lysate harvested at $72 \mathrm{~h}$ post injury from parallel cultures indicates that rapamycin effectively reduces mTOR autophosphorylation (Fig. 4d). Downstream phosphorylation of S6 kinase protein is eliminated by rapamycin treatment (Fig. 4c). While neurons lacking Inpp5f regenerate more robustly than WT neurons, rapamycin does not alter regeneration for either genotype (Fig. $4 a, b$ ). In contrast, rapamycin completely abolishes enhanced regeneration after shRNA-mediated b

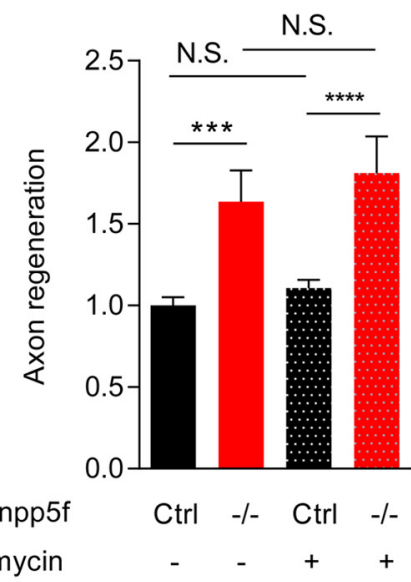

e

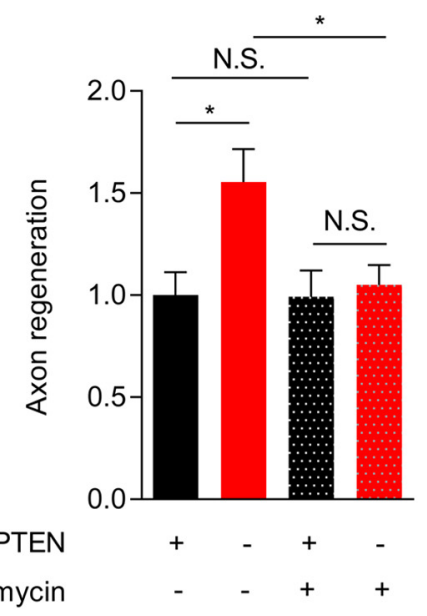

Figure 4. Sensitivity of Inpp5f inactivation induced axon growth to rapamycin. $\boldsymbol{a}$, Regrowth of $\beta$ III-tubulin + axons after scrape, with or without genomic deletion of Inpp5f and with or without presence of rapamycin ( $300 \mathrm{~nm})$. The uninjured zone is at

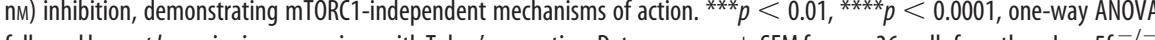
followed by post hoc pairwise comparison with Tukey's correction. Data are mean \pm SEM for $n=36$ wells from three Inpp5f ${ }^{-1-}$ embryos and $n=84$ wells from seven Inpp5f ${ }^{+/-}$or WT embryos per condition. All embryos are cultured independently without injury. Note comparable levels of $\mathrm{p} S 6$ kinase signal in control versus Inpp5f ${ }^{-1-}$ neurons after vehicle treatment, but absence of p56 kinase signal from neurons of either genotype after $3 \mathrm{~d}$ of $300 \mathrm{~nm}$ rapamycin treatment. Scale bar, $100 \mu \mathrm{m}$. $\boldsymbol{d}$, Three days of 300 lysates. $\boldsymbol{e}$, Enhanced regeneration caused by PTEN inactivation is sensitive to rapamycin (300 nm) inhibition. ${ }^{*} p<0.05$, one-way ANOVA followed by Tukey's Post hoc pairwise tests. Data are mean \pm SEM from $n=20-24$ wells per condition.

PTEN inactivation (Fig. 4e). Thus, distinct from PTEN, endogenous Inpp5f suppresses regeneration independently of mTORC1 regulation. This is consistent with more recent data that the primary substrate of Inpp5f is $\mathrm{PI}(4) \mathrm{P}$ and the protein participate in regulation of endocytosis (Hsu et al., 2015; Nakatsu et al., 2015).

\section{Inpp5f-null mice have normal descending spinal tract projections}

To assess the role of Inpp5f in suppressing CNS axon regeneration and functional recovery in vivo, we studied gene-targeted mice lacking Inpp5f. As previously characterized (Zhu et al., 2009), Inpp5f $f^{-l-}$ mice are grossly normal and fertile. Before we assessed the anatomical and behavioral recovery of Inpp5 $\mathrm{f}^{-/-}$ mice from SCI, we sought to understand the baseline anatomy of two descending spinal tracts without injury, the CST and raphespinal tract. We anterogradely traced the CST with BDA and 
a

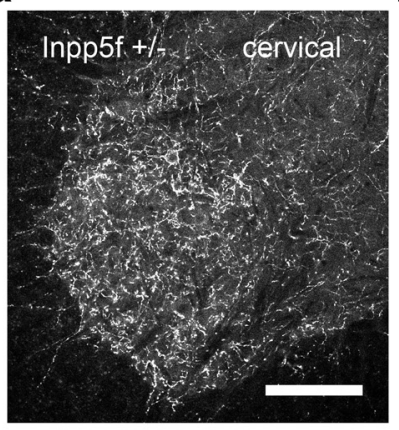

C

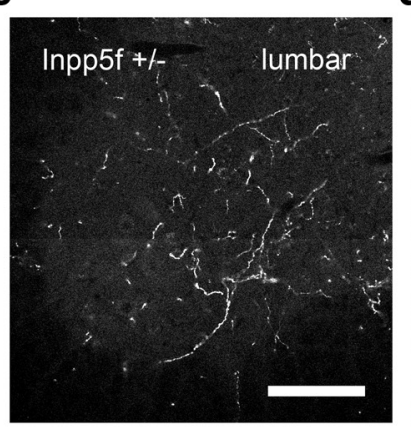

e

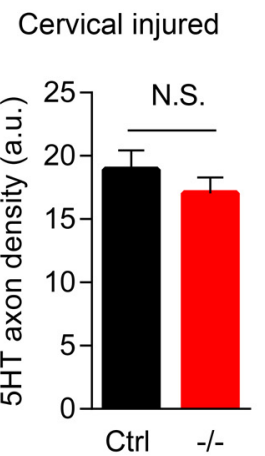

b

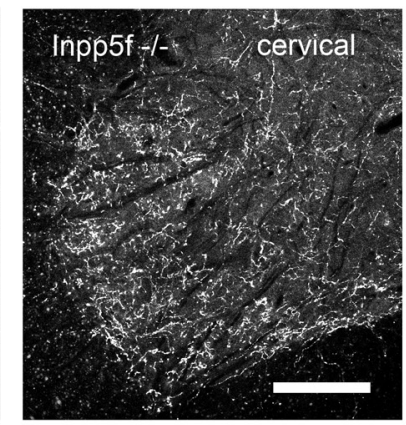

d

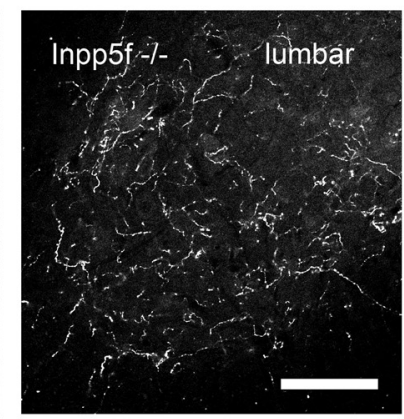

g

\section{Lumbar injured Lumbar uninjured}
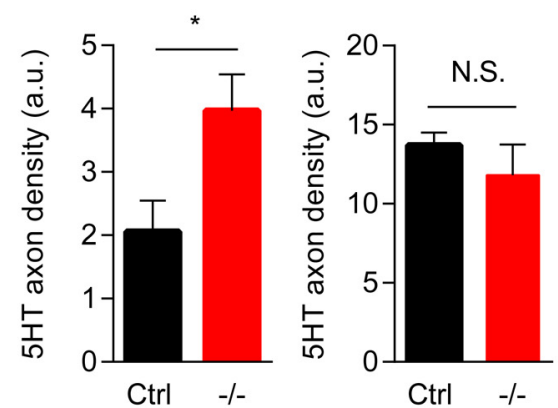

Figure 5. Increased raphespinal tract growth in Inpp5f ${ }^{-1-}$ mice after T7 dorsal hemisection. $\boldsymbol{a}-\boldsymbol{d}$, Representative images of the spinal ventral horn in coronal sections from Inpp5f $f^{+1-}$ and Inpp5f ${ }^{-1-}$ mice. $\boldsymbol{a}, \boldsymbol{b}$, C7 spinal cord. $\boldsymbol{c}, \boldsymbol{d}, \mathrm{L}$ L spinal cord. Scale bar, $100 \mu \mathrm{m}$. Dorsal hemisections were performed in 3- to 5 -month-old mice. Animals were killed 7 weeks after injury. Sections were stained for serotonin (5-HT).e, Quantification of 5 -HT + fiber density in $\boldsymbol{a}$ and $\boldsymbol{b}$. Data are mean \pm SEM for $n=14$ control mice and $n=14 \mathrm{Inpp5f}^{-1-}$ mice. No significant difference. Student's $t$ test. $\boldsymbol{f}$, Quantification of $5-\mathrm{HT}+$ fiber density in $\boldsymbol{c}$ and $\boldsymbol{d}$. Data are mean \pm SEM for $n=14$ control mice and $n=14 \mathrm{Inpp} \mathrm{f}^{-1-}$ mice. ${ }^{*} p<0.05$, Student's $t$ test. $\boldsymbol{g}$, Quantification of 5-HT + fiber density in uninjured L2 spinal ventral horns. Data are

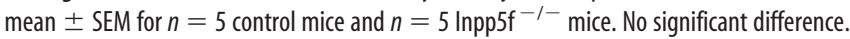
Student's $s$ test. For all quantifications, at least three sections were randomly selected from each mouse for measurement. Control mice include both WT and Inpp5f ${ }^{+/-}$mice. Ctrl, control.

characterized the pattern of BDA + fibers in the spinal cord. WT, Inpp5 $\mathrm{f}^{+-}$, and Inpp $5 \mathrm{f}^{-/-}$littermates have indistinguishable CST anatomy, with most fibers forming a tight bundle in the dorsal column (Fig. $6 a, b$ ). In addition, densities of BDA+ fibers that sprout out from the main CST bundle and terminate in the gray matter are nearly identical in control and Inpp $5 \mathrm{f}^{-/-}$littermates (Fig. 6f). Thus, CST development and maintenance without injury does not require Inpp5f.

We visualized the raphespinal tract by immunostaining serotonin $(5-\mathrm{HT})$, the neurotransmitter uniquely expressed in ra-

phespinal tract axons in the spinal cord. The patterns of 5-HT+ projections are comparable among $\mathrm{WT}$, Inpp $5 \mathrm{f}^{+/-}$, and Inpp $5 \mathrm{f}^{-1-}$ mice. The main tract descends in a diffuse bundle in the intermediolateral white matter and main ramifications are present in the intermediolateral column and in the gray matter. Because 5-HT+ terminals in lumbar ventral horns have a critical role in facilitating lower limb locomotion, we quantified density of 5-HT + terminals in the lumbar ventral horn. The densities are comparable between intact control and Inpp5 $\mathrm{f}^{-/-}$animals (Fig. $5 g$ ). Both CST and raphespinal tracts develop normally without Inpp5f.

\section{Inpp5f-null mice have enhanced lumbar raphespinal growth} after T7 dorsal hemisection

To understand whether Inpp5f titrates neural repair after CNS injury, we created T7 dorsal hemisection SCIs in adult Inpp5 $\mathrm{f}^{-/-}$ and littermate control mice. As a first measure, we visualized $5-\mathrm{HT}+$ terminals in the spinal cord via immunostaining. On day 49 after dorsal hemisection injury, while the density of 5-HT+ terminals in the ventral horn region of cervical enlargement is not different between control and Inpp5f ${ }^{-1-}$ groups (Fig. 5a,b; quantified in $e$ ), the density of ventral horn $5-\mathrm{HT}+$ terminals in lumbar enlargement is twice as high in Inpp5 $\mathrm{f}^{-1-}$ group compared with controls (Fig. $5 c, d$; quantified in $f$ ). Because thoracic dorsal hemisection cuts most but not all raphespinal tract axons, we considered whether increased 5-HT + fiber density below the lesion could be from differences in spared tissue at the lesion center, possibly due to enhanced neuroprotection in Inpp5f ${ }^{-1-}$ mice. However, the spared tissue at lesion center is not different between these two groups ( $25 \pm 4$ vs $34 \pm 4 \%$, mean \pm SEM, $n=$ 14 for each group analyzed for 5 -HT staining; not significant by two-sample $t$ test, $p=0.10$; analysis of all mice in Fig. $8 a, b$ ). Therefore, our observation of increased 5-HT + density below the lesion is most consistent with enhanced serotonergic fiber sprouting after injury in Inpp5 $\mathrm{f}^{-1-}$ animals.

Although initial evaluation of development in Inpp5 $\mathrm{f}^{-/-}$ mice above revealed no alteration in cervical raphespinal fibers (Fig. 5e), we considered whether the pre-injury baseline 5-HT+ density might be greater in the Inpp5 $\mathrm{f}^{-1-}$ lumbar cord. No developmental effect of Inpp5f deletion was detectable in the lumbar region of uninjured mice even though this region showed greater postinjury density (Fig. $5 g$ ). Thus, there is a selective postinjury increase in raphespinal innervation for mice lacking Inpp5f, demonstrating a role for the protein in limiting endogenous neural repair.

\section{Inpp5f-null mice show enhanced CST plasticity after T7 dorsal hemisection}

Because the CST plays a pivotal role in voluntary movement for humans, we investigated the anatomical response of the CST to SCI in Inpp5f-null mice. The T7 dorsal hemisection adult mice received injection of $\mathrm{BDA}$ into the sensorimotor cortex to trace the CST unilaterally on day 35 post injury. After 2 week survival, the total number of BDA+ CST fibers counted in the cervical dorsal columns was comparable between control $(n=15)$ and Inpp5f $^{-1-}(n=11)$ littermates, at $971 \pm 142$ and $1307 \pm 185$ axons per animal, respectively, mean \pm SEM. Incidentally, in two

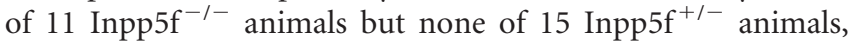
$\mathrm{BDA}+\mathrm{CST}$ axons were observed below the lesion. Consistently, the density of BDA+ CST fibers that branch off the main tract rostral to the SCI and terminate in the gray matter is significantly 

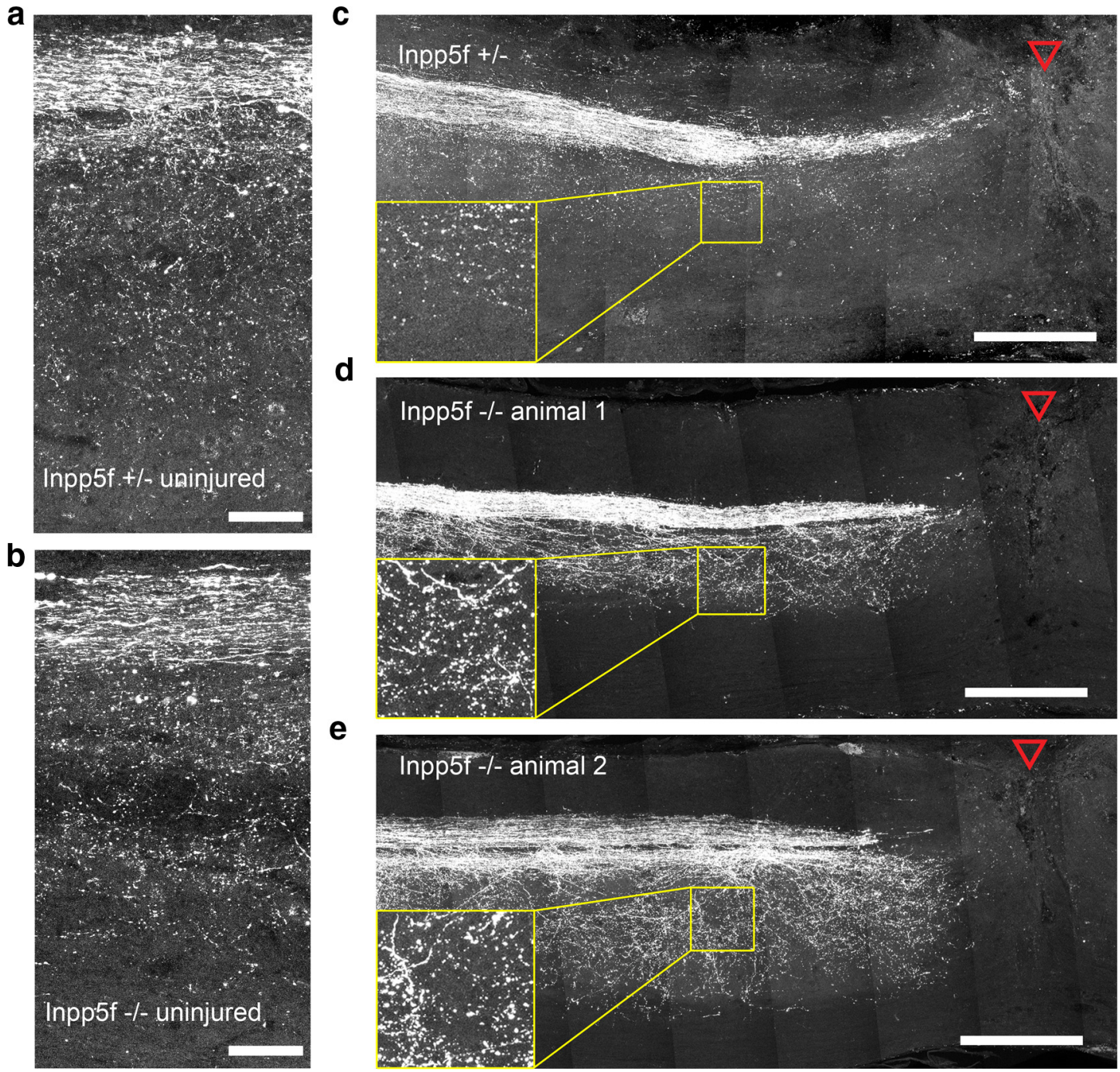

\section{e}
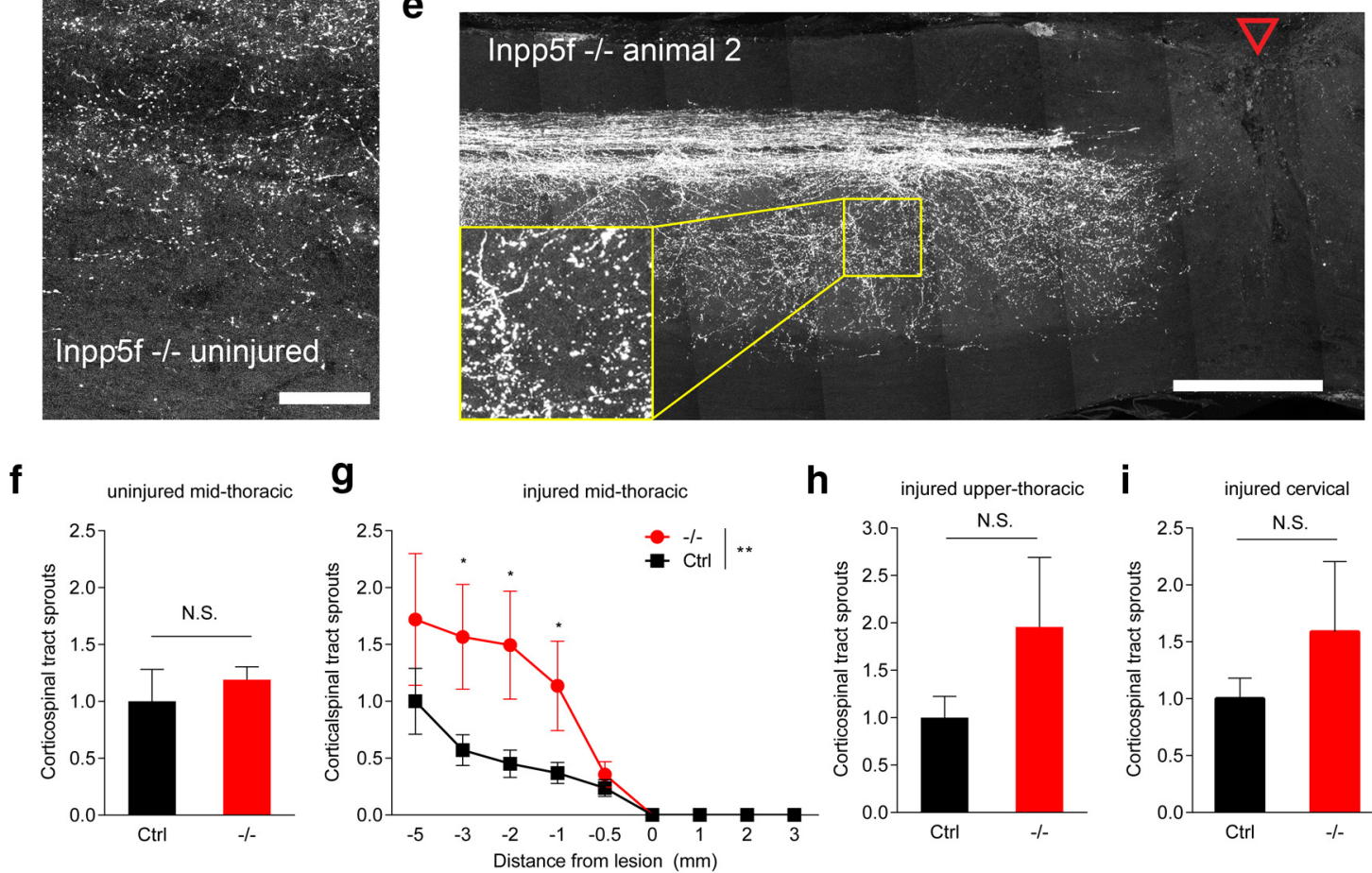

Figure 6. Increased CST plasticity in Inpp5f ${ }^{-/-}$mice after T7 dorsal hemisection. $\boldsymbol{a}, \boldsymbol{b}$, Representative mid-thoracic sagittal section from one Inpp5f ${ }^{+/-}$and one Inpp5f ${ }^{-/-}$uninjured, adult mouse. The CST was labeled by cortical BDA injection; dorsal is up and rostral is left. Note the dense CST bundle near the top and the similar sprouting pattern and density between genotypes. Sprouting from the bundled CST is measured in $\boldsymbol{f}$. Scale bar, $100 \mu \mathrm{m}$. $\boldsymbol{c}-\boldsymbol{e}$, Representative images of sagittal sections from one Inpp5f ${ }^{+/-}$and two Inpp5f ${ }^{-/-}$mice. Dorsal hemisections were performed in 3- to 5-month-old mice. BDA was injected into the right sensorimotor cortex at 5 weeks post injury and mice were killed 2 weeks later. Sections were stained for BDA. Red triangle

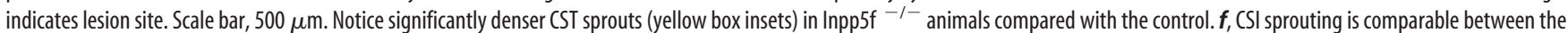
genotypes in mid-thoracic spinal cord in the absence of injury. Measured from section such as in $\boldsymbol{a}$ and $\boldsymbol{b}$. Data are mean \pm SEM for $n=5$ control mice and for $n=5 \mathrm{Inpp} 5 \mathrm{f}^{-/-}$mice. No significant difference between genotypes, Student's $t$ test. $\boldsymbol{g}$, Quantification of the density of labeled CST axons sprouting from the main CST bundle 7 weeks after injury. All labeled fibers outside the main CST bundle on all sagittal sections per animal were counted. Data are mean \pm SEM for $n=15$ for control mice and for $n=11$ Inpp5f $f^{-1-}$ mice. ${ }^{* *} p<0.01$, significant difference between genotypes, one-way repeated-measure ANOVA; ${ }^{*} p<0.05$, at specific distances. $\boldsymbol{h}, \boldsymbol{i}$, A trend of enhanced CST sprouting in favor of Inpp5f knock-out animals after $\mathbf{S C l}$, as detected in cervical $(\boldsymbol{h})$ and upper thoracic spinal cord (i). Data are mean \pm SEM for $n=15$ for control (Ctrl) mice and for $n=11 \mathrm{lnpp5f}{ }^{-1-}$ mice. No significant difference between genotypes, Student's $t$ test. Control mice include both WT and Inpp5f ${ }^{+/-}$mice. 


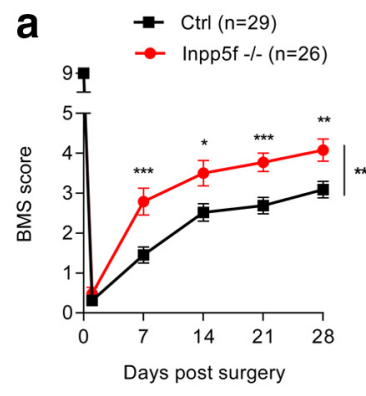

b Before injury

C After injury
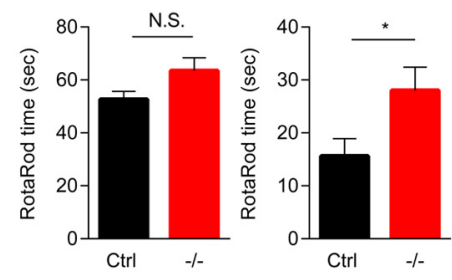

Figure 7. Enhanced behavioral recovery in Inpp5f ${ }^{-1-}$ mice after T7 dorsal hemisection. $\boldsymbol{a}$, Open-field locomotion performance measured by BMS of Inpp5f ${ }^{+/-}$and Inpp5f ${ }^{-/}$mice. Animals were scored on days $0,1,7,14,21,28$, and 35 by two experienced observers blinded of genotype. Data are mean \pm SEM for $n=29$ control (Ctrl) mice and for $n=26 \mathrm{Inpp5f}^{-1-}$ mice. ${ }^{* * *} p<0.001,{ }^{* *} p<0.01,{ }^{*} p<0.05$, significant difference between genotypes, oneway repeated-measure ANOVA across time series followed by post hoc test between genotypes at indicated times. $\boldsymbol{b}, \boldsymbol{c}$, Rotarod performance of control and Inpp5f ${ }^{-1-}$ animals before and after injury. ${ }^{*} p<0.05$, significant difference between genotypes after injury. No significant difference in performance between genotypes before injury. Student's $t$ test. Data are mean \pm SEM for $n=29$ for control mice and for $n=26$ for Inpp5f ${ }^{-1-}$ mice. Control mice include both WT and Inpp5f ${ }^{+/-}$mice.

higher in the Inpp5 $\mathrm{f}^{-1-}$ compared with controls (Fig. $6 c-e$; quantified in $g ; p<0.01$, one-way repeated-measure ANOVA). This difference is the most pronounced in thoracic spinal cord between 1 and $3 \mathrm{~mm}$ rostral to the lesion, where CST terminals are as much as three times more numerous in the Inpp5 $\mathrm{f}^{-1-}$ group compared with the control group $(p<0.05)$. The magnitude of the difference is progressively less pronounced more rostral from the lesion site, while a nonsignificant trend in favor of Inpp $5 \mathrm{f}^{-1-}$ animals persists in upper thoracic spinal cord (Fig. $6 h$ ) and the cervical enlargement (Fig. 6i). Thus, while Inpp5f is not required for CST development and maintenance without injury, removing Inpp5f increases the density of sprouting CST fibers rostral to the lesion.

\section{Inpp5f-null mice show enhanced functional recovery after T7 dorsal hemisection}

To understand if the anatomical plasticity and regeneration observed in Inpp5f deletion mice has functional significance, we tracked locomotor performance of injured mice in two behavioral tests: BMS and rotarod. In the BMS test, while control and Inpp $5 \mathrm{f}^{-/-}$both start at the perfect score of 9 before injury and decrease to scores $<1$ (i.e., close to complete paralysis) one day after injury, Inpp $5 \mathrm{f}^{-1-}$ group recovers significantly more quickly and more completely (Fig. 7a). By day 7 after injury, the Inpp $5 \mathrm{f}^{-/-}$group has an average score of close to 3 . Most animals exhibit extensive ankle movement and some were able to achieve proper paw placement, weight support, and beyond using their hindlimbs. On the other hand, the control group only achieved an average score between 1 and 2 by day 7. Most of animals in the control group exhibit slight to extensive ankle movement with few exhibiting more advanced hindlimb functions. The Inpp $5 \mathrm{f}^{-/-}$group $(n=26)$ maintained their advantage in functional recovery over the control group $(n=29)$ over the following 4 weeks, with a final BMS score of $4.08 \pm 0.29$ versus $3.09 \pm$ 0.21 ( $p<0.001$, one-way repeated-measure ANOVA).

Given the greater BMS recovery of the Inpp5f-null group within $7 \mathrm{~d}$, we considered whether there might be an unexpected neuroprotective effect in addition to an early sprouting effect. We quantified tissue sparing at the epicenter of dorsal hemisection injury (Fig. 8a). Although there was no statistically significant a

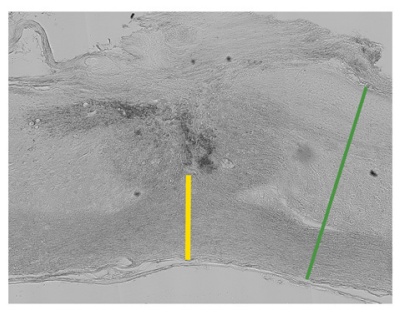

b
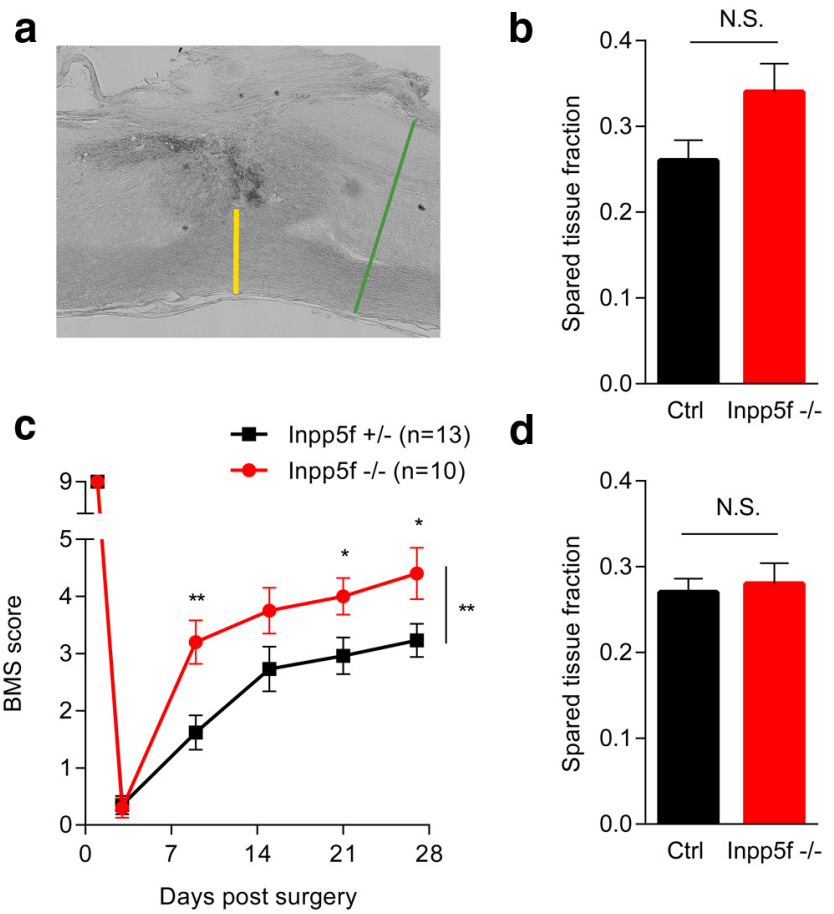

d

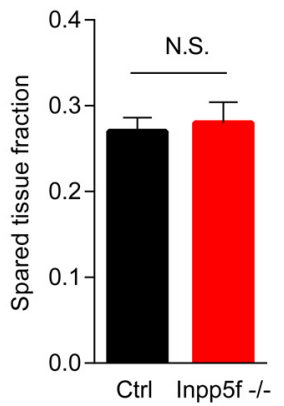

Figure 8. Tissue sparing cannot account for improved recovery in Inpp5f $f^{-1-}$ mice. $a$, Quantification of the extent of tissue sparing. Phase-contrast images of sagittal spinal cord sections were collected from every section in every animal. On each section, the yellow line indicates distance of spared tissue. The green line indicates extent of healthy spinal cord. Spared tissue fraction of each animal was calculated by the ratio of the sum of all yellow lines in each animal and the sum of all green lines in each animal. All measurements were performed blind to genotypes. $\boldsymbol{b}$, Statistically insignificant difference in spared tissue fraction between Inpp5f knock-out and control groups. No significant difference, $p>0.05$ by Student's $t$ test. Data are mean \pm SEM for $n=29$ control mice and for $n=26 \mathrm{Inpp5f}^{-1-}$ mice. c, Improved open-field locomotion recovery in Inpp5f knock-out mice after strictly controlling for differences in spared tissue fraction. This subanalysis only included animals with spared tissue fraction between 0.15

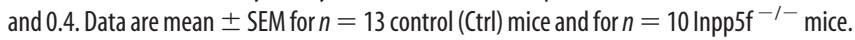
${ }^{*} p<0.05,{ }^{* *} p<0.01$, one-way repeated-measure ANOVA across time series followed by post hoc test between genotypes at indicated times. $\boldsymbol{d}$, No difference in spared tissue fraction between Inpp5f knock-out and control groups in animals used for subanalysis in c. Data are mean \pm SEM for $n=13$ control mice and for $n=10 \mathrm{Inpp5f}^{-1-}$ mice. Control mice include both WT and Inpp5f ${ }^{+/-}$mice.

difference between groups (Fig. $8 b$ ), there is a nonsignificant trend to tissue preservation in the Inpp $5 \mathrm{f}^{-/-}$group. We performed a post hoc secondary analysis to stratify animals by lesion severity, confining the analysis to intermediate tissue loss (Fig. $8 d)$. Even with this stratification, there is a robust enhancement in BMS recovery in Inpp $5 \mathrm{f}^{-1-}$ group compared with controls (Fig. $8 c ; p<0.01$ ). We conclude that the greater BMS recovery after SCI is more likely because of axon growth rather than neuroprotection.

As a secondary outcome measure, the same mouse cohort was assessed for rotarod performance after SCI. While the two genotype groups behave similarly before injury (Fig. 7b), the Inpp $5 \mathrm{f}^{-/-}$group is able to stay on the rotating drum almost twice as long as the control group on day 35 after injury (Fig. $7 c$ ). Together, the BMS and rotarod data demonstrate that greater functional recovery from SCI accompanies greater axonal growth after CNS trauma in mice lacking Inpp5f.

\section{Discussion}

Through an unbiased functional screen, we identified 18 phosphatases that negatively regulate CNS axon growth after injury, 
including 17 phosphatases not previously known to function in this capacity in neurons. Unexpectedly, our screen highlighted metabolism of water-soluble and water-insoluble inositol phosphates as a key pathway that regulates CNS axon growth after injury. Using gene-targeted mice, we specifically investigated how one of the hit genes, Inpp5f (Sac2), suppresses recovery both on the anatomical and functional levels after SCI in vivo. Inactivation of Inpp5f led to enhanced regeneration and sprouting of serotonergic fibers below the injury level, enhanced sprouting of injured corticospinal fibers above the injury level, and enhanced locomotor performance in open-field and rotarod tests. Thus, our study demonstrated the promise of an unbiased functional genomic discovery method and uncovered a previously unknown suppressor of CNS regeneration.

While there is substantially greater locomotor recovery and axonal sprouting after traumatic SCI when the Inpp5f gene is deleted, the most critical anatomical pathways are not defined here. In mice, the CST is dispensable for unskilled locomotor functions as those tested by open-field BMS score and rotarod (Siegel et al., 2015). The raphe nuclei, on the other hand, may provide the basis for enhanced recovery in Inpp5f-null mice. While some intraspinal serotonergic axons are found in mice, the vast majority of serotonergic fibers that we observed in the lumbar spinal cord likely originate from the raphe nuclei in the brainstem. Given the high expression of Inpp5f in brainstem and the activating effect of raphespinal innervation in the spinal cord, enhanced regeneration and sprouting of the raphespinal tract can be a major driver of enhanced functional recovery observed in Inpp5f-null mice. Directly testing this hypothesis by inactivating the raphe nuclei using pharmacogenetic tools will be of significant interest (Siegel et al., 2015). In addition to the CST and raphespinal tract, two other descending projections may contribute to enhanced functional recovery in Inpp5f knock-out mice. Rubrospinal tract and reticulospinal tract are both important for recovery of locomotor functions after SCI (Schucht et al., 2002). Inpp5f is expressed in the red nuclei and the reticular formations in adult mice and humans [Allen Brain Atlas (Lein et al., 2007)]. Injecting retrograde tracers into spinal cord below the lesion coupled to a complete lesion may be able to shed light on changes in regeneration properties of these two tracts in Inpp5f-null mice.

This study focused on the screen of phosphatases and the validation of Inpp5f as an axon growth regeneration inhibitor. Initial biochemical studies pointed to the 5-position of $\mathrm{PI}(4,5) \mathrm{P} 2$ and $\mathrm{PI}(3,4,5) \mathrm{P} 3$ as the preferred substrates of Inpp5f (Minagawa et al., 2001), and raised the possibility that it may mimic the regeneration action of PTEN. However, rapamycin does not reduce the increased regeneration observed in Inpp5f-null neurons (Fig. 4) or after Inpp5f silencing (our unpublished observations), suggesting alternative mechanisms and substrates. Recent work from our group and others identified the 4-position of $\mathrm{PI}(4) \mathrm{P}$ as the substrate in nonneuronal cells (Hsu et al., 2015; Nakatsu et al., 2015). At a cellular level, the primary role of Inpp5f (Sac2) is in the regulation of endocytic events (Hsu et al., 2015; Nakatsu et al., 2015). There is preexisting evidence that membrane traffic plays a key role in axonal extension. A recent high-profile study described a link between ER and endosome contact in mediating axonal extension (Raiborg et al., 2015). Over many years, membrane addition and subtraction from distal tip of the axon has been appreciated as crucial for regulating growth rates. We showed that semaphorins, as extracellular cues inhibiting extension and collapsing growth cones, stimulate local and massive macropinocytosis at the growth cone (Fournier et al., 2000). In C. elegans, loss of function in any of three endocytosis genes (unc-26/synaptojanin, unc-57/endophilin, and unc-41/stonin) re- sults in decreased regeneration (Chen et al., 2011). Multiple studies have demonstrated that new membrane is added to the distal axon tip during growth, and the growth cone is known to be highly enriched in endomembranous stacks (Cheng and Reese, 1987; Lockerbie et al., 1991; Diefenbach et al., 1999; Hazuka et al., 1999; Tojima et al., 2007; Kolpak et al., 2009). Dendritic branching in Drosophila is intimately connected with Golgi outposts (Ye et al., 2007). Thus, Inpp5f regulation of distal membrane traffic may be crucial for effective regeneration via regulation of membrane addition.

We focused our attention on Inpp5f because of its robust phenotype in the primary screen and follow-up assays as well as Inpp5f's favorable safety profile in contrast to that of PTEN as a potential therapeutic target. In mice, Inpp5f-null animals develop and reproduce normally and exhibit no adverse phenotypes under basal conditions. Despite two recent correlative studies (Kim et al., 2014; Nalls et al., 2014), human INPP5F loss of function is not known to cause adverse medical conditions. In contrast, loss-of-function PTEN mutations in humans are frequent drivers in glioblastoma, endometrial cancer, and prostate cancer cases (Hollander et al., 2011). In mice, whole-body removal of PTEN in adult mice via conditional Cre-mediated genomic excision leads to $100 \%$ lethality within $28 \mathrm{~d}$ (data not shown). Overall, INPP5F's favorable safety profile adds to its promise as a potential therapeutic target to improve recovery after SCI.

\section{References}

Atwal JK, Pinkston-Gosse J, Syken J, Stawicki S, Wu Y, Shatz C, TessierLavigne M (2008) PirB is a functional receptor for myelin inhibitors of axonal regeneration. Science 322:967-970. CrossRef Medline

Basso DM, Fisher LC, Anderson AJ, Jakeman LB, McTigue DM, Popovich PG (2006) Basso Mouse Scale for locomotion detects differences in recovery after spinal cord injury in five common mouse strains. J Neurotrauma 23:635-659. CrossRef Medline

Blackmore MG, Moore DL, Smith RP, Goldberg JL, Bixby JL, Lemmon VP (2010) High content screening of cortical neurons identifies novel regulators of axon growth. Mol Cell Neurosci 44:43-54. CrossRef Medline

Bradbury EJ, Moon LD, Popat RJ, King VR, Bennett GS, Patel PN, Fawcett JW, McMahon SB (2002) Chondroitinase ABC promotes functional recovery after spinal cord injury. Nature 416:636-640. CrossRef Medline

Buchser WJ, Slepak TI, Gutierrez-Arenas O, Bixby JL, Lemmon VP (2010) Kinase/phosphatase overexpression reveals pathways regulating hippocampal neuron morphology. Mol Syst Biol 6:391. CrossRef Medline

Cafferty WB, Duffy P, Huebner E, Strittmatter SM (2010) MAG and OMgp synergize with Nogo-A to restrict axonal growth and neurological recovery after spinal cord trauma. J Neurosci 30:6825-6837. CrossRef Medline

Chen L, Wang Z, Ghosh-Roy A, Hubert T, Yan D, O'Rourke S, Bowerman B, Wu Z, Jin Y, Chisholm AD (2011) Axon regeneration pathways identified by systematic genetic screening in C. elegans. Neuron 71:1043-1057. CrossRef Medline

Chen MS, Huber AB, van der Haar ME, Frank M, Schnell L, Spillmann AA, Christ F, Schwab ME (2000) Nogo-A is a myelin-associated neurite outgrowth inhibitor and an antigen for monoclonal antibody IN-1. Nature 403:434-439. CrossRef Medline

Cheng TP, Reese TS (1987) Recycling of plasmalemma in chick tectal growth cones. J Neurosci 7:1752-1759. Medline

Dergham P, Ellezam B, Essagian C, Avedissian H, Lubell WD, McKerracher L (2002) Rho signaling pathway targeted to promote spinal cord repair. J Neurosci 22:6570-6577. Medline

Diefenbach TJ, Guthrie PB, Stier H, Billups B, Kater SB (1999) Membrane recycling in the neuronal growth cone revealed by FM1-43 labeling. J Neurosci 19:9436-9444. Medline

Duffy P, Wang X, Siegel CS, Tu N, Henkemeyer M, Cafferty WB, Strittmatter SM (2012) Myelin-derived ephrinB3 restricts axonal regeneration and recovery after adult CNS injury. Proc Natl Acad Sci U S A 109:5063-5068. CrossRef Medline

Ertürk A, Hellal F, Enes J, Bradke F (2007) Disorganized microtubules underlie the formation of retraction bulbs and the failure of axonal regeneration. J Neurosci 27:9169-9180. CrossRef Medline

Fisher D, Xing B, Dill J, Li H, Hoang HH, Zhao Z, Yang XL, Bachoo R, 
Cannon S, Longo FM, Sheng M, Silver J, Li S (2011) Leukocyte common antigen-related phosphatase is a functional receptor for chondroitin sulfate proteoglycan axon growth inhibitors. J Neurosci 31:14051-14066. CrossRef Medline

Fournier AE, Nakamura F, Kawamoto S, Goshima Y, Kalb RG, Strittmatter SM (2000) Semaphorin3A enhances endocytosis at sites of receptor-Factin colocalization during growth cone collapse. J Cell Biol 149:411-422. CrossRef Medline

Fournier AE, GrandPre T, Strittmatter SM (2001) Identification of a receptor mediating Nogo-66 inhibition of axonal regeneration. Nature 409: 341-346. CrossRef Medline

Fournier AE, Takizawa BT, Strittmatter SM (2003) Rho kinase inhibition enhances axonal regeneration in the injured CNS. J Neurosci 23:14161423. Medline

Fry EJ, Chagnon MJ, López-Vales R, Tremblay ML, David S (2010) Corticospinal tract regeneration after spinal cord injury in receptor protein tyrosine phosphatase sigma deficient mice. Glia 58:423-433. Medline

GrandPré T, Nakamura F, Vartanian T, Strittmatter SM (2000) Identification of the Nogo inhibitor of axon regeneration as a Reticulon protein. Nature 403:439-444. CrossRef Medline

Hammarlund M, Nix P, Hauth L, Jorgensen EM, Bastiani M (2009) Axon regeneration requires a conserved MAP kinase pathway. Science 323:802806. CrossRef Medline

Hazuka CD, Foletti DL, Hsu SC, Kee Y, Hopf FW, Scheller RH (1999) The sec6/8 complex is located at neurite outgrowth and axonal synapseassembly domains. J Neurosci 19:1324-1334. Medline

Hellal F, Hurtado A, Ruschel J, Flynn KC, Laskowski CJ, Umlauf M, Kapitein LC, Strikis D, Lemmon V, Bixby J, Hoogenraad CC, Bradke F (2011) Microtubule stabilization reduces scarring and causes axon regeneration after spinal cord injury. Science 331:928-931. CrossRef Medline

Hollander MC, Blumenthal GM, Dennis PA (2011) PTEN loss in the continuum of common cancers, rare syndromes and mouse models. Nat Rev Cancer 11:289-301. CrossRef Medline

Hsu F, Hu F, Mao Y (2015) Spatiotemporal control of phosphatidylinositol 4-phosphate by Sac2 regulates endocytic recycling. J Cell Biol 209:97-110. CrossRef Medline

Huebner EA, Kim BG, Duffy PJ, Brown RH, Strittmatter SM (2011) A multi-domain fragment of Nogo-A protein is a potent inhibitor of cortical axon regeneration via Nogo receptor 1. J Biol Chem 286:18026-18036. CrossRef Medline

Kim HS, Li A, Ahn S, Song H, Zhang W (2014) Inositol Polyphosphate-5Phosphatase F (INPP5F) inhibits STAT3 activity and suppresses gliomas tumorigenicity. Sci Rep 4:7330. CrossRef Medline

Kim JE, Liu BP, Park JH, Strittmatter SM (2004) Nogo-66 receptor prevents raphespinal and rubrospinal axon regeneration and limits functional recovery from spinal cord injury. Neuron 44:439-451. CrossRef Medline

Kolpak AL, Jiang J, Guo D, Standley C, Bellve K, Fogarty K, Bao ZZ (2009) Negative guidance factor-induced macropinocytosis in the growth cone plays a critical role in repulsive axon turning. J Neurosci 29:10488-10498. CrossRef Medline

Lang BT, Cregg JM, DePaul MA, Tran AP, Xu K, Dyck SM, Madalena KM, Brown BP, Weng YL, Li S, Karimi-Abdolrezaee S, Busch SA, Shen Y, Silver J (2015) Modulation of the proteoglycan receptor PTPsigma promotes recovery after spinal cord injury. Nature 518:404-408. CrossRef Medline

Lee DH, Luo X, Yungher BJ, Bray E, Lee JK, Park KK (2014) Mammalian target of rapamycin's distinct roles and effectiveness in promoting compensatory axonal sprouting in the injured CNS. J Neurosci 34:1534715355. CrossRef Medline

Lein ES, Hawrylycz MJ, Ao N, Ayres M, Bensinger A, Bernard A, Boe AF, Boguski MS, Brockway KS, Byrnes EJ, Chen L, Chen TM, Chin MC, Chong J, Crook BE, Czaplinska A, Dang CN, Datta S, Dee NR, Desaki AL, et al. (2007) Genome-wide atlas of gene expression in the adult mouse brain. Nature 445:168-176. CrossRef Medline

Lewandowski G, Steward O (2014) AAVshRNA-mediated suppression of PTEN in adult rats in combination with salmon fibrin administration enables regenerative growth of corticospinal axons and enhances recovery of voluntary motor function after cervical spinal cord injury. J Neurosci 34:9951-9962. CrossRef Medline
Lockerbie RO, Miller VE, Pfenninger KH (1991) Regulated plasmalemmal expansion in nerve growth cones. J Cell Biol 112:1215-1227. CrossRef Medline

Majerus PW (1992) Inositol phosphate biochemistry. Annu Rev Biochem 61:225-250. CrossRef Medline

Minagawa T, Ijuin T, Mochizuki Y, Takenawa T (2001) Identification and characterization of a sac domain-containing phosphoinositide 5-phosphatase. J Biol Chem 276:22011-22015. CrossRef Medline

Moore DL, Blackmore MG, Hu Y, Kaestner KH, Bixby JL, Lemmon VP, Goldberg JL (2009) KLF family members regulate intrinsic axon regeneration ability. Science 326:298-301. CrossRef Medline

Mukhopadhyay G, Doherty P, Walsh FS, Crocker PR, Filbin MT (1994) A novel role for myelin-associated glycoprotein as an inhibitor of axonal regeneration. Neuron 13:757-767. CrossRef Medline

Nakatsu F, Messa M, Nández R, Czapla H, Zou Y, Strittmatter SM, De Camilli $\mathrm{P}$ (2015) Sac2/INPP5F is an inositol 4-phosphatase that functions in the endocytic pathway. J Cell Biol 209:85-95. CrossRef Medline

Nalls MA, Pankratz N, Lill CM, Do CB, Hernandez DG, Saad M, DeStefano AL, Kara E, Bras J, Sharma M, Schulte C, Keller MF, Arepalli S, Letson C, Edsall C, Stefansson H, Liu X, Pliner H, Lee JH, Cheng R, et al. (2014) Large-scale meta-analysis of genome-wide association data identifies six new risk loci for Parkinson's disease. Nat Genet 46:989-993. CrossRef Medline

Nikulina E, Tidwell JL, Dai HN, Bregman BS, Filbin MT (2004) The phosphodiesterase inhibitor rolipram delivered after a spinal cord lesion promotes axonal regeneration and functional recovery. Proc Natl Acad Sci U S A 101:8786-8790. CrossRef Medline

Park KK, Liu K, Hu Y, Smith PD, Wang C, Cai B, Xu B, Connolly L, Kramvis I, Sahin M, He Z (2008) Promoting axon regeneration in the adult CNS by modulation of the PTEN/mTOR pathway. Science 322:963-966. CrossRef Medline

Raiborg C, Wenzel EM, Pedersen NM, Olsvik H, Schink KO, Schultz SW, Vietri M, Nisi V, Bucci C, Brech A, Johansen T, Stenmark H (2015) Repeated ER-endosome contacts promote endosome translocation and neurite outgrowth. Nature 520:234-238. CrossRef Medline

Schucht P, Raineteau O, Schwab ME, Fouad K (2002) Anatomical correlates of locomotor recovery following dorsal and ventral lesions of the rat spinal cord. Exp Neurol 176:143-153. CrossRef Medline

Shen Y, Tenney AP, Busch SA, Horn KP, Cuascut FX, Liu K, He Z, Silver J, Flanagan JG (2009) PTPsigma is a receptor for chondroitin sulfate proteoglycan, an inhibitor of neural regeneration. Science 326:592-596. CrossRef Medline

Siegel CS, Fink KL, Strittmatter SM, Cafferty WB (2015) Plasticity of intact rubral projections mediates spontaneous recovery of function after corticospinal tract injury. J Neurosci 35:1443-1457. CrossRef Medline

Smith PD, Sun F, Park KK, Cai B, Wang C, Kuwako K, Martinez-Carrasco I, Connolly L, He Z (2009) SOCS3 deletion promotes optic nerve regeneration in vivo. Neuron 64:617-623. CrossRef Medline

Sun F, Park KK, Belin S, Wang D, Lu T, Chen G, Zhang K, Yeung C, Feng G, Yankner BA, He Z (2011) Sustained axon regeneration induced by codeletion of PTEN and SOCS3. Nature 480:372-375. CrossRef Medline

Tojima T, Akiyama H, Itofusa R, Li Y, Katayama H, Miyawaki A, Kamiguchi H (2007) Attractive axon guidance involves asymmetric membrane transport and exocytosis in the growth cone. Nat Neurosci 10:58-66. CrossRef Medline

Wang KC, Koprivica V, Kim JA, Sivasankaran R, Guo Y, Neve RL, He Z (2002) Oligodendrocyte-myelin glycoprotein is a Nogo receptor ligand that inhibits neurite outgrowth. Nature 417:941-944. CrossRef Medline

Ye B, Zhang Y, Song W, Younger SH, Jan LY, Jan YN (2007) Growing dendrites and axons differ in their reliance on the secretory pathway. Cell 130:717-729. CrossRef Medline

Zhu W, Trivedi CM, Zhou D, Yuan L, Lu MM, Epstein JA (2009) Inpp5f is a polyphosphoinositide phosphatase that regulates cardiac hypertrophic responsiveness. Circ Res 105:1240-1247. CrossRef Medline

Zou J, Zhang C, Marjanovic J, Kisseleva MV, Majerus PW, Wilson MP (2012) Myotubularin-related protein (MTMR) 9 determines the enzymatic activity, substrate specificity, and role in autophagy of MTMR8. Proc Natl Acad Sci U S A 109:9539-9544. CrossRef Medline 